\title{
2019 ITAA Pre-conference Workshop: Understanding the Requirements and Expectations for Preparing the Self-Study Report for TAPAC Accreditation Review
}

Coordinators: Kathleen Rees and Carol Warfield

Presenters: Kathleen Rees, Carol Warfield, Elena Karpova, Sherry Schofield, Nancy Miller, Linda Welters, Leigh Southward, Farrell Doss, Elizabeth Bye, Jane Hegland, Rinn Cloud, and Andy Reilly

Overview: The workshop was designed for program representatives and administrators either planning for or in the process of preparing the Self-Study Report for TAPAC Accreditation Review. The focus was on preparing the Self-Study Report and related materials to most effectively communicate how the program addresses and meets TAPAC Accreditation Standards. Following an overview of the Self-Study document, TAPAC members provided insight regarding documentation required to address each of the seven TAPAC Accreditation Standards. Examples of suggestions and pointers to help communicate requisite program information are provided below.

Standard 1 General Criteria: This standard requires basic program information be provided, including verification that the program is a baccalaureate program within a university that is regionally or nationally accredited and has published program mission, goals/objectives, and program competencies; a designated program coordinator; and meets minimum faculty requirements. While some components included in Standard 1 are addressed more fully in other Standards, it is important that the program document shows that there are at least two full-time faculty with responsibilities in the program, each of whom must have a minimum of a master's degree. In addition, the program must verify that including both full- and part-time faculty, there must be at least 2.0 FTE teaching assigned to the program. For purposes of calculating FTE, a three credit course counts as a 0.25 FTE for a semester.

Standard 2 Mission, Vision, Values, and Planning: This standard focuses on planning documents developed to guide the program, including the program's mission and goals statements, as well as the program's strategic plan. Components within this standard require that the program demonstrate the manner in which the program's mission statement aligns with the institution's mission, vision, and values and that there is a clear set of program goals

Page 1 of 4

Published under a Creative Commons Attribution License (https://creativecommons.org/licenses/by/4.0/), which permits unrestricted use, distribution, and reproduction in any medium, provided the original work is properly cited.

ITAA Proceedings, \#76 - https: //itaaonline.org 
that support the program's mission statement. In addition, it is essential to provide evidence that the program is guided by a strategic plan. Depending on the organizational structure in which the program operates, the strategic plan may be a stand-alone document that applies only to the program, but aligned with the university plan - or it may be embedded within a larger strategic plan of the administrative unit with the program's components clearly identifiable.

Standard 3 Administration: This standard addresses resources and policies, student/faculty ratios, designated program leader, faculty governance, and industry interactions. The narrative related to Standard 3 provides an explanation of how resource allocation decisions are made at the institution/college level and at the program level. The narrative also includes information regarding the program's budgets and expenditures for the current academic year and two prior academic years. Student /faculty ratios should be separate by option or track, if those exist. The Program Coordinator position description should address clearly defined roles and expectations. Finally, while industry interactions may or may not involve a formal advisory board, an explanation regarding the manner in which industry partners contribute to keeping the curriculum current needs to be included.

Standard 4 Faculty: This standard addresses policies and procedures related to the program's faculty members. The goal is to ensure that the number of faculty members, as well as their qualifications, are sufficient to meet the program's goals and student learning outcomes. It is important to provide context by comparing the program faculty's teaching and research expectations with those of other programs within the department and/or departments within the college. In addition to providing evidence (i.e., faculty CV's, tables, numbers, and links), it is important to include a narrative explaining faculty workload, professional development opportunities, and various policies pertaining to faculty workload. Full-time faculty are expected to teach at least $60 \%$ of required classes for each major or option included in the accreditation review.

Standard 5 Students: This standard includes a variety of components related to the program's student body, including policies related to admission, retention, and dismissal; academic, career, and internship advising; diversity and inclusion; student records; student involvement; and grade appeals. Data regarding composition of the student body during the current and past two years is requested in tabular form and should be provided for each major, concentration,

Page 2 of 4

Published under a Creative Commons Attribution License (https://creativecommons.org/licenses/by/4.0/), which permits unrestricted use, distribution, and reproduction in any medium, provided the original work is properly cited.

ITAA Proceedings, \#76 - https://itaaonline.org 
and/or option within the program. Additional information regarding student retention rates, number of students graduating, and student-faculty ratios should be provided for the current and past two years. The narrative for Standard 5 should describe processes, resources, and evaluation for academic, internship, and career advising, as well as explaining how the program complies with university policy related to diversity and inclusion. Finally, information should be included regarding student involvement in professional organizations, and a description of policy and processes regarding student records and grade appeals.

Standard 6 Facilities and Equipment: This standard focuses on confirming that space, equipment and other resources are adequate to meet the program's mission and goals, as well as to accommodate the number of students enrolled in the program. Proof of compliance with current ADA requirements typically exists at the university level and can be documented via links to the university policies and practices. The narrative for Standard 6 can include brief statements, bullet points, charts and/or floor plan to identify how space is used, maintenance and/or enhancement plans, resource trends to support space and equipment, square footage allocation, and equipment and technology available to support the program.

Standard 7 Curriculum and Learning Outcomes: This standard addresses the program curricula and student learning outcomes (SLO) which are derived from the program goals, program mission, college mission, and university mission. The program must verify that $40 \%$ of the required courses are program specific, and the program must demonstrate that this is met for each concentration or option included in the program seeking accreditation. SLOs based on the ITAA Meta-goals need to be imbedded within required courses, and each SLO must be related to a level of Bloom's Taxonomy. In addition, the report must show that courses are scaffolded so that there is a progression of knowledge and skills from introductory to advanced courses. The program must further indicate how each SLO is assessed and met using direct measures (those obtained from the student via test questions, homework or project assignments, etc.) and/or indirect measures from a third party (e.g., findings from focus groups with employers, intern coordinators, advisors, or boards). It is not expected that each SLO in every course be assessed every year; instead assessment of SLOs can be designed on a rotation basis so they are measured every two to three years, or as deemed appropriate by the program. Finally, the program must demonstrate through curriculum maps of four-year plans that the program is designed so students who attend full-time can complete the program in four years.

Page 3 of 4

(c) 2019 The author(s). Published under a Creative Commons Attribution License (https://creativecommons.org/licenses/by/4.0/), which permits unrestricted use, distribution, and reproduction in any medium, provided the original work is properly cited.

ITAA Proceedings, \#76 - https://itaaonline.org 
Summary: The self-study report is designed to enable the program to "tell its story" and highlight areas of program successes as well as challenges faced and plans of action to overcome such challenges by the program in delivering a high-quality baccalaureate degree program. Programs are encouraged to begin the self-study process early in order to provide adequate time to gather data and provide an opportunity for various stakeholders to share input and fully participate in the process of preparing the self-study document. For additional information and instructions, individuals are directed to the Self-Study Report Guide which can be accessed through the TAPAC website www.itaaonline.org/mpage/TAPAC8 or contact the TAPAC Executive Director (executive director@tapac-online.org ).

Published under a Creative Commons Attribution License (https://creativecommons.org/licenses/by/4.0/), which permits unrestricted use, distribution, and reproduction in any medium, provided the original work is properly cited. 